\title{
Non-Vitamin K Oral Anticoagulants Associated Bleeding and Its Antidotes
}

\author{
Thorsten Steiner, ${ }^{\mathrm{a}, \mathrm{b}}$ Martin Köhrmann, ${ }^{\mathrm{c}}$ Peter D. Schellinger,, ${ }^{\mathrm{c}, \mathrm{d}}$ Georgios Tsivgoulis ${ }^{\mathrm{e}, \mathrm{f}}$ \\ ${ }^{a}$ Department of Neurology, Frankfurt Hoechst Hospital, Frankfurt, Germany \\ ${ }^{b}$ Department of Neurology, Heidelberg University Hospital, Heidelberg, Germany \\ 'Department of Neurology, Essen University Hospital, Essen, Germany \\ ${ }^{d}$ Department of Neurology and Neurogeriatry, Johannes Wesling Medical Center Minden, University Clinic RUB, Minden, Germany \\ eSecond Department of Neurology, Attikon University Hospital, National and Kapodistrian University of Athens, Athens, Greece \\ fDepartment of Neurology, University of Tennessee Health Science Center, Memphis, TN, USA
}

Oral anticoagulant-associated intracerebral hemorrhage (OAC-ICH) accounts for nearly 20\% of all ICH. The number of patients with an indication for oral anticoagulant therapy (OAT) increases with increasing age. OAT became less complicate with the introduction of non-vitamin $\mathrm{K}$ oral anticoagulants (NOAC) OAT because of easier handling, favorable risk-benefit profile, reduced rates of $\mathrm{ICH}$ compared to vitamin $\mathrm{K}$ antagonists and no need for routine coagulation testing. Consequently, despite a better safety profile of NOAC the number of patients with OAC-ICH will increase. The mortality and complication rates of $\mathrm{OAC}-\mathrm{ICH}$ are high and therefore they are the most feared complication of OAT. Immediate normalization of coagulation is the main goal and therefore knowledge of pharmacodynamics and coagulation status is essential. Laboratory measurements of anticoagulant activity in NOAC patients is challenging as specific tests are not widely available. More accessible tests such as the prothrombin time and activated partial thromboplastin time have important limitations. In dabigatran-associated ICH $5 \mathrm{~g}$ Idarucizumab should be administered. In rivaroxaban and apixaban-associated ICHs administration of andexanet alpha should be considered. Prothrombin complex concentrate may be considered if andexanet alpha is not available or in case of an ICH associated with edoxaban.

Keywords Apixaban; Dabigatran; Edoxaban; Rivaroxaban; Idarucizumab; Andexanet alpha
Correspondence: Thorsten Steiner Department of Neurology, Frankfurt Hoechst Hospital, Gotenstr. 6-8, 56929 Frankfurt, Germany Tel: +49-69-31062932

Fax: $+49-69-31063747$

E-mail: thorsten_steiner@med. uni-heidelberg.de

Received: August 11, 2018 Revised: September 12, 2018 Accepted: September 12, 2018

\section{Introduction}

Ten to $17 \%$ of all strokes are intracerebral hemorrhages $(\mathrm{ICHs}){ }^{1}$ Oral anticoagulant-associated ICH (OAC-ICH) accounts for nearly $20 \%$ of all ICH. ${ }^{2}$ Non-valvular atrial fibrillation (NAF) is one of the most common indications for $\mathrm{OAC}$ and the incidence has continued to rise, because of advances in early detection and treatment. ${ }^{3.4}$ Anticoagulants are recommended for a broad range of indications. If assuming 70\% of 5 million Europeans with NAF were on OAC (approximately $40 \%$ on non-vitamin K oral antico- agulant [NOAC], and $30 \%$ on vitamin $\mathrm{K}$ antagonists [VKAs] $)^{5}$ and an average rate of $0.6 \%$ OAC-ICH per year, this corresponds to 21,000 cases OAC-ICH each year in Europe.

NOACs were developed to directly inhibit thrombin or factor $X a$. Randomized controlled trial (RCT) data and meta-analyses provide solid evidence for a favorable risk-benefit profile of NOACs when compared with warfarin and with low-molecular-weight heparin for primary and secondary prevention in patients with NAF and treatment/prevention of venous thromboembolism, respectively. ${ }^{6,7}$ Advantages of NOACs are easier 
handling, reduction in fatal and life-threatening bleeding (as ICH), and fewer drug and food interactions. For these reasons and because of current and expected approval of different reversal agents the use of NOAC will further increase. ${ }^{8}$ Consequently, the number of patients with OAC-ICH will increase, despite the lower risk of intracranial bleeding of NOACs (compared to VKAs). ${ }^{9}$

The aim of this review is to address the clinical management of patients with NOAC-associated ICH.

\section{Laboratory measurements}

Testing of the anticoagulant activity of the varying NOACs is complex. Routine coagulation tests such as prothrombin time (PT)/international normalized ration (INR) or partial thrombin time (PT) may be within normal limits and will only provide qualitative information. In comatose or aphasic patients OAC might go undetected unless laboratory methods such as ecarin clotting time (ECT), thrombin time ( $\Pi$ ), factor-Xa assays are applied. ${ }^{10,11}$ Particularly in this situation information on last intake of a NOAC may not be available. Suggestions for use of laboratory measurements and specialized assays and their interpretation are presented in Tables 1 and $2 .^{12,13}$

\section{Coagulation tests for factor lla (thrombin) inhibitors (dabigatran)}

The most specific tests for assessing the anticoagulant activity of dabigatran are the diluted thrombin time (dTT), the ECT, and the ecarin chromogenic assay. These tests closely correlate with dabigatran levels measured by the reference standard method,

Table 1. Suggestions for laboratory measurements of NOAC to exclude clinically relevant* drug levels

\begin{tabular}{|c|c|c|c|c|}
\hline \multirow{2}{*}{ Drug } & \multicolumn{2}{|c|}{ In case specialized assays are not available } & \multicolumn{2}{|r|}{ In case specialized assays are available } \\
\hline & Suggested test & Interpretation & Suggested test & Interpretation \\
\hline \multirow[t]{3}{*}{ Dabigatran } & \multirow[t]{3}{*}{$\Pi, \mathrm{aPTT}$} & Normal $\Pi \pi$ excludes clinically relevant levels & Diluted TT & \multirow{3}{*}{$\begin{array}{l}\text { Normal results probably exclude clinically rele- } \\
\text { vant levels }\end{array}$} \\
\hline & & $\begin{array}{l}\text { Prolonged } \Pi \text { does not discriminate between } \\
\text { clinically important and insignificant levels }\end{array}$ & ECT & \\
\hline & & $\begin{array}{l}\text { Normal aPTT usually excludes clinically rele- } \\
\text { vant levels, if a sensitive reagent is used. }\end{array}$ & ECA & \\
\hline $\begin{array}{l}\text { Apixaban, rivaroxa- } \\
\text { ban, or edoxaban }\end{array}$ & None & $\begin{array}{l}\text { Normal PT and aPTT do not exclude clinically } \\
\text { relevant levels }\end{array}$ & Anti-Xa & $\begin{array}{c}\text { Absent chromogenetic anti-Xa assay activity } \\
\text { probably excludes clinically relevant levels }\end{array}$ \\
\hline
\end{tabular}

Modified from Tomaselli et al., with permission from Elsevier. ${ }^{12}$

NOAC, non-vitamin K oral anticoagulant; $\Pi$, thrombin time; aPTT, activated partial thromboplastin time; ECT, ecarin clotting time; ECA, ecarin chromogenic assay; anti-Xa, anti-factor Xa.

*"Clinically relevant": NOAC levels that may contribute to bleeding or surgical bleeding risk. The minimal NOAC level for bleeding risk is unknown; in patients with serious bleeding consideration of reversal was recommended when NOAC level is $>50 \mathrm{ng} / \mathrm{mL}$, and for patients requiring an invasive procedure with high bleeding risk and a DOAC level $>30 \mathrm{ng} / \mathrm{mL}^{13}$ (this includes all NOACs).

Table 2. Suggestions for laboratory measurements to determine whether on-therapy or above on-therapy NOAC levels are present

\begin{tabular}{lllll}
\hline \multirow{2}{*}{ Drug } & \multicolumn{2}{c}{ In case specialized assays are not available } & \multicolumn{2}{c}{ In case specialized assays are available } \\
\cline { 2 - 5 } Dabigatran & Suggested test & Interpretation & Suggested test & Comment \\
\hline aPTT & $\begin{array}{l}\text { Prolonged aPTT suggests that on-therapy or above on-therapy } \\
\text { levels are present }\end{array}$ & Diluted TT
\end{tabular}

ECT

Normal aPTT may not exclude on-therapy levels, particularly if a ECA relatively insensitive aPTT reagent is used

\begin{tabular}{|c|c|c|c|c|}
\hline Apixaban & PT & $\begin{array}{l}\text { Prolonged PT suggests that on-therapy or above on-therapy } \\
\text { levels are present } \\
\text { Normal PT may not exclude on-therapy or above on-therapy } \\
\text { levels, particularly if a relatively insensitive PT reagent is used }\end{array}$ & Anti-Xa & $\begin{array}{l}\text { Useful for quantification of } \\
\text { plasma drug levels only } \\
\text { when calibrated with the } \\
\text { drug of interest }\end{array}$ \\
\hline $\begin{array}{l}\text { Rivaroxaban or edoxa- } \\
\text { ban }\end{array}$ & PT & $\begin{array}{l}\text { Prolonged PT suggests that on-therapy or above on-therapy } \\
\text { levels are present } \\
\text { Normal PT may not exclude on-therapy levels, particularly if a } \\
\text { relatively insensitive PT reagent is used }\end{array}$ & Anti-Xa & $\begin{array}{l}\text { Useful for quantification of } \\
\text { plasma drug levels only } \\
\text { when calibrated with the } \\
\text { drug of interest }\end{array}$ \\
\hline
\end{tabular}

Modified from Tomaselli et al., with permission from Elsevier. ${ }^{12}$

NOAC, non-vitamin K oral anticoagulant; aPT, activated partial thromboplastin time; $\Pi$, thrombin time; $E C T$, ecarin clotting time; ECA, ecarin chromogenic assay; PT, prothrombin time; anti-Xa, anti-factor $X a$. 
liquid chromatography-tandem mass spectrometry. ${ }^{12,14,15} \Pi$ and activated partial thromboplastin time (aPTT) may be used alternatively for qualitative assessments. ${ }^{16}$ The most sensitive test to detect the presence of dabigatran is the $\Pi$, even at very low drug concentrations. A normal-range $\Pi$ assay excludes the presence of clinically relevant plasma concentrations ("clinically relevant": NOAC levels that may contribute to bleeding or surgical bleeding risk) of dabigatran, but a prolonged $\Pi$ does not discriminate between clinically important and irrelevant drug concentrations. ${ }^{9,12}$ The aPTT is prolonged by dabigatran. But the correlation between dabigatran plasma concentrations and aPTT is non-linear. Still, a normal aPT does not reliably exclude the presence of clinically relevant drug levels, especially when a relatively insensitive aPTT reagent is used. ${ }^{14,15,17}$ The PT/INR is also prolonged by dabigatran but is not sensitive enough to detect clinically relevant drug concentrations.

\section{Coagulation tests for factor $\mathrm{Xa}$ inhibitors (rivaroxaban, apixaban, edoxaban)}

Chromogenic anti-factor Xa assays are the preferred tests for assessing the anticoagulant activity of factor $\mathrm{Xa}$ inhibitors, and correlate closely with plasma drug levels measured by liquid chromatography-tandem mass spectrometry. ${ }^{14,15}$ A variety of anti-factor Xa assays correlate with plasma concentrations of rivaroxaban, apixaban, and edoxaban. All these tests must be calibrated individually for each type of therapy being assessed and are increasingly available worldwide. ${ }^{18}$ Rivaroxaban prolongs PT/INR, with the sensitivity depending on used reagent. PT/INR may be useful for qualitative assessment of edoxaban and rivaroxaban as well, if an anti-factor $\mathrm{Xa}$ assay is not available (comparable to the aPTT in dabigatran). ${ }^{19}$ However, depending on the sensitivity of the PT reagent, a normal PT does not exclude clinically relevant levels. ${ }^{14,15}$ A prolonged PT suggests the presence of clinically relevant apixaban levels, but a normal PT or aPTT does not exclude relevant drug levels. ${ }^{14,15,19}$ Direct factor $X a$ inhibitors do not influence $T$.

\section{Point of care testing in NOAC treated patients}

Point of care testing (POCT) of coagulation was proven to be of great value in accelerating emergency treatment. ${ }^{20}$ In VKA patients the PT/INR can be measured rapidly with the CoaguChek (Roche, Basel, Switzerland), a PT/INR-POCT designed for VKA monitoring. Specific POCTs for NOACs are under investigation but not available in clinical routine yet. It was shown, that clinically relevant plasma concentrations of rivaroxaban can be qualitatively ruled out using the CoaguChek, but this method is not suitable for apixaban and dabigatran. ${ }^{21,22}$ An INR below 1.0 (measured with CoaguChek) can rule out clinically relevant plasma concentrations of rivaroxaban $(<100 \mathrm{ng} / \mathrm{mL})$.

The Hemochron Signature (ITC, Edison, NJ, USA) is another coagulation POCT that uses a different PT/INR assay as the CoaguChek and has additional measuring capabilities for aPT and activated clotting time (ACT). ${ }^{23}$ The Hemochron Signature is also responsive to rivaroxaban and dabigatran. ${ }^{22,24}$ The diagnostic accuracy of Hemochron Signature to qualitatively rule out relevant concentrations of apixaban, rivaroxaban, and dabigatran in real-life patients was tested in a prospective observational clinical trial. ${ }^{23}$ In this trial ACT was measured using ACT plus $(\mathrm{ACT}+)$ and $\mathrm{ACT}$-low range (ACT-LR) test cards that contain different reagents and cover different measurement ranges. It was shown, that POCT results of PT/INR and ACT+ correlated with both, rivaroxaban and dabigatran concentrations, but only insufficiently with apixaban. So far, no convincing explanation was provided for the different reaction to the two factor Xa-inhibitors. Authors recommended the use of $\mathrm{ACT}+$ test cards for rivaroxaban and PT/INR test cards for dabigatran, although both can be detected with PT/INR or ACT+ POCT cards. In conclusion, Hemochron Signature can be used to qualitatively rule out relevant concentrations of rivaroxaban and dabigatran, suggesting that this method may be a more versatile alternative for guiding emergency treatment as compared to the CoaguChek which only responded to rivaroxaban. The development of reliable POCT for all the four NOACs remains a major priority.

\section{Managing NOAC-associated ICH}

\section{General comments on NOAC-ICH}

The annual rates for ICH in NOAC treated patients is $0.23 \%$ to $0.50 \% .{ }^{25}$ The reduction of fatal bleeding in NOAC treated patients observed in RCTs and patient registries have all occurred without the availability of any specific reversal agents for the NOACs. Interestingly, a recent meta-analysis reported that the relative risk of NOACs (compared to VKAs) for fatal ICH was 0.46 (95\% confidence interval, 0.36 to 0.58$)$ without any evidence of heterogeneity across included RCTs. ${ }^{26}$ General treatment of NOAC-ICH does not differ from treatment of spontaneous $\mathrm{ICH}$ and we therefore refer to $\mathrm{ICH}$ treatment guidelines for further information. ${ }^{27}$ Still, we emphazise the importance of lowering systolic blood pressure: The three three large RCTs on blood pressure lowering in $\mathrm{ICH}$ demonstrated that intensive blood pressure lowering below systolic pressure of $140 \mathrm{~mm} \mathrm{Hg}$ (above $120 \mathrm{~mm} \mathrm{Hg}$ ) is safe. ${ }^{28-30}$ The latest meta-analysis demonstrates significant prevention of hematoma expansion (HE) when systolic blood pressure is lowered below $140 \mathrm{~mm} \mathrm{Hg} .{ }^{31}$ The retrospective cohort study by Kuramatsu et al. ${ }^{32}$ revealed 
lower rates of $\mathrm{HE}$ in patients with reduction in systolic blood pressure to less than $160 \mathrm{~mm} \mathrm{Hg}$ within 4 hours.

Clinicians need to pay attention to comorbidities such as thrombocytopenia, uremia or liver disease, as these can worsen bleeding and subsequently outcome. Furthermore, concomitant treatments such as antiplatelet therapy need to be considered. ${ }^{12}$ All NOACs are more or less dependent on renal function. This needs to be taken into consideration when assessing clinically relevant drug levels..$^{33}$

\section{Bleeding classification}

Bleeding complications are divided into major and non-major bleedings in clinical trials. ${ }^{34}$ This simple categorization is also relevant in clinical routine, because major bleedings should be treated differently from non-major bleedings. The definition of a major bleeding includes a bleeding associated with hemodynamic compromise, a bleeding that occurs in an anatomically critical site, requires transfusion or results in a hemoglobin drop of $2 \mathrm{~g} / \mathrm{dL} .^{12}$ Critical bleeds are considered as those that compromise an organs function: the most feared is an intracranial hemorrhage. ${ }^{12}$

\section{Hematoma expansion in NOAC-ICH}

Anticoagulation is a contributing rather than a causative factor for the occurrence of ICH. Underlying causes of OAC associated $\mathrm{ICH}$ and spontaneous ICH might be the same, with OAC being only a precipitating factor. ${ }^{35-37}$ The characteristics and natural history of NOAC-associated ICH in the acute phase are largely unknown and prospective data on HE or on the effect of hemostatic management in patients receiving NOACs are limited and conflicting. The prospective registry Registry of Acute Stroke Under New Oral Anticoagulants (RASUNOA) showed that HE is frequent in NOAC-ICH (38\%; in 17 of 45 subjects), has a high mortality (28\% at 3 months) and an unfavorable outcome among the survivors (65\%). ${ }^{38}$ Other observational reports and a recent meta-analysis argue that NOAC-associated ICH presents with smaller baseline hematoma volumes and lower likelihood of $\mathrm{HE}$ compared to VKA-ICH. ${ }^{39}$ These observations are indirectly supported by the largest to date cohort study that compared inhospital mortality rates among patients with VKA- $(n=15,036)$ and NOAC-ICH $(n=4,918)$ in the Get With The Guidelines Registry. The in-hospital mortality rate was lower in NOAC-ICH (adjusted risk difference in favor of NOACs, 5.7\%). This difference was further accentuated among those patients pre-treated with antiplatelet therapy in addition to OACs (adjusted risk difference in favor of NOACs, 15\%). ${ }^{40}$

\section{OAC reversal strategies and reversal agents}

\section{Reversal strategies for factor II Inhibitor (dabigatran) associated ICH}

Idarucizumab (in early trials also called Dabi-Fab or BI 655075) has been approved 2016 as "Praxbind" in many countries for the reversal of dabigatran in patients with uncontrolled bleeding or in need for urgent emergency-procedure (Table 3). Idarucizumab is a humanized monoclonal antibody fragment that binds dabigatran with high affinity (affinity of idarucizumab for dabigatran is approximately 350 times that of dabigatran for thrombin ${ }^{16}$ ). The RE-VERSE AD (Reversal of Dabigatran Anticoagulant Effect with Idarucizumab) study, investigated dabigatran-treated patients with either ongoing severe or life-threatening hemorrhage, or in need for emergency procedures. Patients were treated with idarucizumab $5 \mathrm{~g}(2 \times 2.5 \mathrm{~g}$ intravenously); the primary endpoint was the maximum reversal of the anticoagulant effect of dabigatran, which was assessed by $\mathrm{dTT}$ or ECT. ${ }^{41}$ The primary endpoint was reached in 100\% of the patients, and reversal was maintained for 24 hours in most patients. Concerning safety aspects, the treatment with idarucizumab was safe with no significant adverse events, especially no procoagulatory effects or complications such as venous thrombosis. ${ }^{41,42}$

Idarucizumab should be administered as soon as the diagnosis of a dabigatran-associated ICH is proven. The results of a recently published nationwide retrospective registry reporting

Table 3. Suggestions for reversal agents

\begin{tabular}{|c|c|c|c|c|c|}
\hline \multirow[b]{2}{*}{ Anticoagulant } & \multicolumn{5}{|c|}{ Reversal agent } \\
\hline & $\begin{array}{c}\text { Idarucizumab } \\
5 \mathrm{~g} \text { i.v. }\end{array}$ & Andexanet alfa* & $\begin{array}{l}4 \text { Factor PCC } \\
50 \mathrm{U} / \mathrm{kg} \text { i.v. }\end{array}$ & $\begin{array}{l}\text { Activated PCC } \\
50 \mathrm{U} / \mathrm{kg} \text { i.v. }\end{array}$ & FFP \\
\hline Factor lla inhibitor (dabigatran) & First line & Not indicated & Second line & Second line & Not indicated \\
\hline $\begin{array}{l}\text { Factor Xa inhibitors (rivaroxaban, apixaban, } \\
\text { and edoxaban) }\end{array}$ & Not indicated & First line ${ }^{+}$ & Second line ${ }^{+}$ & Second line & Not indicated \\
\hline
\end{tabular}

Dosing: Idarucizumab=5 $\mathrm{g}_{i}^{42}$ PCC (4 factor and activated PCC) for NOAC-reversal=50 U/ $/ \mathrm{kg}_{1}^{12,57}$ maximum dose of 4,000 U for activated PCC. ${ }^{10,12,44,45}$ i.v., intravenous; PCC, prothrombin complex concentrate; FFP, fresh frozen plasma.

*Apixaban or rivaroxaban $>7$ hours previously: bolus $400 \mathrm{mg}$, infusion $480 \mathrm{mg}$ over 120 minutes. Enoxaparin or rivaroxaban $\leq 7$ hours previously: bolus 800 $\mathrm{mg}$, infusion $960 \mathrm{mg}$ over 120 minutes; $^{+}$Approved for rivaroxaban and apixaban; ${ }^{*}$ When andexanet alfa unavailable. 
favorable outcomes in 12 dabigatran-associated ICH patients treated with idarucizumab further highlight the favorable therapeutic potential of this reversal agent. More specifically, rapid reversal of the anticoagulant activity was documented in all patients, hematoma growth was detected in only two cases $(17 \%)$ and only one patient died during hospitalization (8\%). ${ }^{43}$

If idarucizumab is unavailable, prothrombin complex concentrates (PCCs) have been proposed as a plausible, but unproven therapy to reverse the anticoagulant effects of NOACs, but no clinically beneficial effect of PCC was observed in dabigatran-related ICH in registries. ${ }^{38}$ Still, based on limited data from animal, ex vivo and human studies PCC or aPCC may be administered with a dose of $50 \mathrm{U} / \mathrm{kg}^{10,44,45}$ Administration of fresh frozen plasma (FFP) or activated recombinant factor VII ( $\mathrm{rFVlla)}$ is not recommended for reversal of dabigatran. ${ }^{46}$

If reversal agents are not available, diuresis with intravenous fluids may enhance renal excretion of dabigatran. Activated charcoal ( $50 \mathrm{~g}$ ) may be used if the drug was ingested within last 2 to 4 hours. $^{16}$ Acute hemodialysis may be useful, because only about one-third of dabigatran is bound to plasma proteins. But hemodialysis may take too long if not started early enough. ${ }^{9,16}$

\section{Reversal strategies for factor Xa Inhibitor} (rivaroxaban, apixaban, edoxaban) associated ICH Andexanet alfa ( $r$-antidote or PRT064445, "andexanet") is a reversal agent that is designed to neutralize the anticoagulant effects of both direct and indirect factor Xa inhibitors. ${ }^{47}$ The U.S. Food and Drug Administration approved andexanet for the use in apixaban and rivaroxaban-associated emergencies in May 2018 in the United States (Table 3). ${ }^{48}$ Andexanet is a recombinant modified human factor $\mathrm{Xa}$ decoy protein with a similar structure as endogenous factor $X a$. Andexanet is cataIytically inactive but retains the ability to bind factor Xa inhibitors in the active site with high affinity. ${ }^{49} \mathrm{~A}$ bolus and 2-hour infusion of andexanet alfa rapidly reversed the anticoagulant effects of apixaban and rivaroxaban in older healthy volunteers. ${ }^{47}$ The open-label single-group ANNEXA-4 study (NCT 02329327) evaluated andexanet in factor Xa inhibitor-treated patients with major bleeding who had taken a factor $X a$ inhibitor within 18 hours before start of treatment. According to an interim analysis $(n=67)$ administration of andexanet alfa in critical bleeding resulted in effective hemostasis in 80\% of patients with ICH. ${ }^{50}$ Two different dosages and application-procedures are required for a particular factor $\mathrm{Xa}$ inhibitor and time since last intake (Table 3). The short half-life of andexanet alfa may be the reason for why factor $X a$ activity returns back to what was seen in placebo treated volunteers within 1 to 3 hours of stopping the infusion. ${ }^{12,47,50}$ Other questions arise from a possible procoagulant effect. Until now it is unclear if observed thromboembolic events in the interim analysis were due to withheld anticoagulation or if andexanet had an impact, as andexanet binds to the natural anticoagulant tissue factor pathway inhibitor, which could produce a procoagulant effect. ${ }^{12,49}$

Andexanet is still not widely available outside the USA and so far not approved in Europe or Asia, so that coagulation factor supplementation, e.g., with PCC or aPCC although larger scale prospective data are lacking. Serial in vivo/ex vivo experiments and animal experimental studies on the effect of PCC, aPCC, fibrinogen concentrate, or rFVlla in NOAC demonstrated different, partially contradictory results. ${ }^{10}$ Available clinical data on the use of four- and three-factor PCCs are conflicting. Whereas Levi et al. ${ }^{51}$ demonstrated that three- and four-factor PCCs did have a significant normalizing effect on several coagulation tests when compared to saline, Gerner et al. ${ }^{52}$ did not see an effect of four-factor PCC on HE in their retrospective analysis. However, the study, demonstrated a significant effect of blood pressure lowering on HE. In case of rivaroxaban, PT, and endogenous thrombin potential were completely reversed by four-factor PCC $50 \mathrm{IU} / \mathrm{kg}$, partially by $37.5 \mathrm{IU} / \mathrm{kg}$ but not by $25 \mathrm{IU} / \mathrm{kg}^{53}$ In apixaban, partial and dose-dependent reversal was achieved by PCC 25 and $37.5 \mathrm{IU} / \mathrm{kg}$; but data on $50 \mathrm{IU} / \mathrm{kg}$ are not available..$^{54}$ In edoxaban, full reversal was achieved by $50 \mathrm{IU} / \mathrm{kg}$ and partially by 10 and $25 \mathrm{lU} / \mathrm{kg} .^{55}$

Concerning dosing of four-factor PCCs EHRA-guidelines recommend a dose of $50 \mathrm{U} / \mathrm{kg}^{56}$ As there are no randomised data regarding dosing in factor $\mathrm{Xa}$ inhibitor treated patients with major bleeding, a dose of $50 \mathrm{U} / \mathrm{kg}$ is also recommended for aPCC, instead of the higher dosing up to $100 \mathrm{U} / \mathrm{kg}$ typically administered in hemophilia patients. ${ }^{12,57}$ APCC may be more potent but also have higher thrombogenic potential..$^{58}$

As there is no sufficient evidence for FFP, plasma should not be administered in the setting of FXa-associated ICH. Due to a higher thromboembolic risk of $\mathrm{rFVIla}$ compared to PCC, rFVIla can be administered, but it is recommended to prefer PCC as nonspecific reversal strategy. ${ }^{46}$ We recommend not to use rFVIla.

In case PCC is not available or is not suitable, administration of activated charcoal $(50 \mathrm{~g})$ may be considered. Dialysis is not suitable for factor Xa inhibitors because of high plasma protein binding (85\% to 95\% for apixaban and rivaroxaban, $65 \%$ for edoxaban). Therefore, plasmapheresis seems more plausible in these cases, ${ }_{11}^{11}$ but is only reasonable if applied shortly after intake of the drug. 
Reversal agents under development

Another target-specific reversal agent in clinical proving is ciraparantag (also called PER977, aripazine), a small synthetic molecule, that might reverse the activity of all NOACs-both the factor $\mathrm{Xa}$ and factor Ila inhibitors-as well as certain forms of heparin..$^{59}$ The water-soluble cationic molecule binds via a noncovalent charge-charge interaction to direct and indirect inhibitors of factor $\mathrm{Xa}$ and thrombin and prevents the anticoagulant from binding to its endogenous target once it is bound. ${ }^{60}$ Ciraparantag is still in the early stages of development and several phase II studies for the different NOAC are currently conducted (NCT01688830 or NCT02104947 (dabigatran); NCT017 58432 (rivaroxaban and apixaban). For edoxaban (NCT01826266) the study demonstrated rapid and maintained (24 hours) reversal of whole-blood clotting times in 80 volunteers. ${ }^{60,61}$ In an in vivo study on rat-tail-transection bleeding assays ciraparantag reversed anticoagulation with each of the new oral agents and did not bind to plasma proteins, including albumin, no procoagulant effects have been identified. Adverse effects were flushing symptoms and dysgeusia. ${ }^{60}$ To our knowledge there is no phase III trial conducted, so that approval of this potential reversal agent remains speculative.

Finally, modified thrombin molecules as specific reversal agent for dabigatran have been investigated. Genetically changed and therefore inactive or trypsinized thrombin molecules (S195A-Ila or YT-S195Alla) could antagonize the anticoagulative effect of dabigatran in an in vivo analysis and in a mouse model. ${ }^{62}$ There are no clinical data available for this reversal agent.

\section{Considerations for restarting anticoagulation}

For a long time, ICH has been considered as contraindication for further anticoagulation. The risk of recurrent $\mathrm{ICH}$ while on OAC was assumed double as high as with the overall recurrence risk of $\mathrm{ICH}$. The mortality rate associated with recurrent $\mathrm{ICH}$ can be as high as 50\%. ${ }^{63,64}$ On the other hand there is the high risk of systemic and cerebral embolism in patients with NAF. Data concerning this conflicting issue are rare and personal opinion generally shapes the decision. Furthermore, the labels of the NOAC state that ICH constitutes a contraindication for OAC and therefore re-starting anticoagulation after ICH would be off-label use. The decision on restarting OAC means to balance between two risks: ischemic stroke and rebleeding and is often made on the basis of a risk-benefit analysis for the individual patient. ${ }^{9,65}$ In most cases there is net clinical benefit in favor of restarting OAC after an ICH if there is a proven indication for $\mathrm{OAC}^{66}$ and especially in patients with deep hemispheric ICH. ${ }^{63,67,68}$ In a German retrospective cohort study OAC was resumed in 23.9\% of VKA-ICH survivors. There were fewer cerebral ischemic events and no difference in recurrent ICH in patients who received OAC after an $\mathrm{ICH}$ compared to those who did not. Furthermore, OAC resumption was significantly related to a decreased long-term mortality. ${ }^{32}$ The individual patient data meta-analysis of the three cohorts (including the German) confirmed these results and revealed that there are no differences between patients with lobar and deep $\mathrm{ICH}$ and also not between patients with possible and probable cerebral amyloid angiopathy. ${ }^{69}$ An analysis of Danish registries also found a significant reduction in ischemic stroke and mortality in post- $\mathrm{ICH}$ anticoagulated patients. ${ }^{70,71}$

The relative reduced risk of ICH with NOACs compared to warfarin renders NOACs the preferred drugs when resuming $\mathrm{OAC}$ after ICH. However, data from a prospective randomised phase II trial (APACHE-AF trial, NCT02565693, clinicaltrials.gov) investigating this for apixaban are not available yet. For dabigatran an observational study showed, that resumption of OAC with either dabigatran or warfarin after a major bleeding event was associated with increased survival and stroke-free survival compared with discontinuing anticoagulation. In addition, dabigatran was associated with lower risk of recurrent hemorrhage than warfarin. ${ }^{66}$ Physicians should consider the availability of a NOAC-specific reversal agent when selecting the NOAC agent for resuming anticoagulation in patients with prior NOAC-ICH.

Suggested factors that contribute to the risk-benefit assessment of restarting anticoagulation are patient's age, renal function (with worsening of renal insufficiency leading to elevated OAC levels), the location of $\mathrm{ICH}$, presence of the apolipoprotein $\varepsilon 2$ or $\varepsilon 4$ alleles, and greater number of cerebral microbleeds on MRI. ${ }^{9}$ In the meantime, physicians might consider whether left atrial appendage occlusion is an option in selected patients with an increased bleeding risk due to the prior NOAC-associated ICH.1-74

The optimum timing of the resumption of anticoagulation is another challenge with conflicting evidence. Lower rates of ischemic strokes can already be observed at 2 weeks in patients who were restarted on OAC compared to those who were not in the geRman-widE mulTicenter Analysis of oRal Anticoagulation-associated intraCerebral hEmorrhage (RETRACE) study. ${ }^{32}$ These data were not available when the current American Heart Association were already published in 2015. They advocate avoidance of oral anticoagulation for at least 4 weeks, in ICH patients without mechanical heart valves and indication of anticoagulation (Class Ilb/Level of Evidence B recommendation). ${ }^{75}$ We propose to restart NOAC not earlier than 
2 to 4 weeks after ICH, taking into consideration the aforementioned risk factors and particularly blood pressure, as anticoagulation should not be re-started in patients with elevated blood pressure and a clear indication for OAC. We also advocate to include patients in RCTS (e.g., APACHE-AF trial, NCT02565693, clinicaltrials.gov) whenever possible.

\section{Conclusions}

Although mortality in ICH has been reduced during the last decades and NOACs appear to have a better safety profile compared to VKAs, oral anticoagulant therapy- $\mathrm{ICH}$ is frequent and treatment challenging. Physicians should be aware, that restoring coagulation and lowering blood pressure as soon as possible are crucial in order to prevent HE. More available coagulation tests for NOACs and POCTs for emergency situations may help to manage these patients in future. Further investigations are warranted concerning reversal agents, which will hopefully lead to a reduction of mortality and disability of these critically ill patients.

\section{Disclosure}

Thorsten Steiner received speaker fees and consultations fees from Boehringer-Ingelheim, Bayer, BMS Pfizer, and Daiichy Sankyo. Peter D. Schellinger has received speaker and consultation fees from Boehringer-Ingelheim, Bayer, BMS Pfizer, and Daiichy Sankyo. Georgios Tsivgoulis has received speaker and consultation fees from Boehringer-Ingelheim, Bayer, and Daiichy Sankyo.

\section{Acknowledgments}

We thank Corinna Epple for her contribution to the content of the article.

\section{References}

1. Sacco S, Marini C, Toni D, Olivieri L, Carolei A. Incidence and 10 -year survival of intracerebral hemorrhage in a population-based registry. Stroke 2009;40:394-399.

2. Flaherty ML. Anticoagulant-associated intracerebral hemorrhage. Semin Neurol 2010;30:565-572.

3. Alotaibi GS, Wu C, Senthilselvan A, McMurtry MS. Secular trends in incidence and mortality of acute venous thromboembolism: the AB-VTE population-based study. Am J Med 2016;129:879.

4. Writing Group Members, Mozaffarian D, Benjamin EJ, Go AS,
Arnett DK, Blaha MJ, et al. Heart disease and stroke statistics-2016 update: a report from the American heart association. Circulation 2016;133:e38-e360.

5. Steinberg BA, Gao H, Shrader P, Pieper K, Thomas L, Camm $\mathrm{AJ}$, et al. International trends in clinical characteristics and oral anticoagulation treatment for patients with atrial fibrillation: results from the GARFIELD-AF, ORBIT-AF I, and ORBITAF II registries. Am Heart J 2017;194:132-140.

6. Ruff CT, Giugliano RP, Braunwald E, Hoffman EB, Deenadayalu N, Ezekowitz MD, et al. Comparison of the efficacy and safety of new oral anticoagulants with warfarin in patients with atrial fibrillation: a meta-analysis of randomised trials. Lancet 2014;383:955-962.

7. Yao X, Abraham NS, Alexander GC, Crown W, Montori VM, Sangaralingham $L R$, et al. Effect of adherence to oral anticoagulants on risk of stroke and major bleeding among patients with atrial fibrillation. J Am Heart Assoc 2016;5:e003074.

8. Ruff CT, Giugliano RP, Antman EM. Management of bleeding with non-vitamin $\mathrm{K}$ antagonist oral anticoagulants in the era of specific reversal agents. Circulation 2016;134:248-261.

9. Epple C, Steiner T. Acute stroke in patients on new direct oral anticoagulants: how to manage, how to treat? Expert Opin Pharmacother 2014;15:1991-2001.

10. Eerenberg ES, Kamphuisen PW, Sijpkens MK, Meijers JC, Buller HR, Levi M. Reversal of rivaroxaban and dabigatran by prothrombin complex concentrate: a randomized, placebocontrolled, crossover study in healthy subjects. Circulation 2011;124:1573-1579.

11. Steiner T, Böhm M, Dichgans $M$, Diener HC, Ell C, Endres $M$, et al. Recommendations for the emergency management of complications associated with the new direct oral anticoagulants (DOACs), apixaban, dabigatran and rivaroxaban. Clin Res Cardiol 2013;102:399-412.

12. Tomaselli GF, Mahaffey KW, Cuker A, Dobesh PP, Doherty JU, Eikelboom JW, et al. 2017 ACC expert consensus decision pathway on management of bleeding in patients on oral anticoagulants: a report of the American College of Cardiology task force on expert consensus decision pathways. J Am Coll Cardiol 2017;70:3042-3067.

13. Levy JH, Ageno W, Chan NC, Crowther M, Verhamme $P$, Weitz Jl, et al. When and how to use antidotes for the reversal of direct oral anticoagulants: guidance from the SSC of the ISTH. J Thromb Haemost 2016;14:623-627.

14. Cuker A, Siegal DM, Crowther MA, Garcia DA. Laboratory measurement of the anticoagulant activity of the non-vitamin $\mathrm{K}$ oral anticoagulants. J Am Coll Cardiol 2014;64:1128-1139.

15. Samuelson BT, Cuker A, Siegal DM, Crowther M, Garcia DA. Laboratory assessment of the anticoagulant activity of direct 
oral anticoagulants: a systematic review. Chest 2017;151:127138.

16. van Ryn J, Stangier J, Haertter S, Liesenfeld KH, Wienen $W_{\text {, }}$ Feuring $M$, et al. Dabigatran etexilate: a novel, reversible, oral direct thrombin inhibitor: interpretation of coagulation assays and reversal of anticoagulant activity. Thromb Haemost 2010;103:1116-1127.

17. Cuker A. Laboratory measurement of the non-vitamin $\mathrm{K}$ antagonist oral anticoagulants: selecting the optimal assay based on drug, assay availability, and clinical indication. J Thromb Thrombolysis 2016;41:241-247.

18. Samama MM, Contant G, Spiro TE, Perzborn E, Guinet $C$, Gourmelin $Y$, et al. Evaluation of the anti-factor Xa chromogenic assay for the measurement of rivaroxaban plasma concentrations using calibrators and controls. Thromb Haemost 2012;107:379-387.

19. Cuker $A$, Husseinzadeh $H$. Laboratory measurement of the anticoagulant activity of edoxaban: a systematic review. $J$ Thromb Thrombolysis 2015;39:288-294.

20. Rizos T, Herweh $C_{1}$ Jenetzky $E_{1}$ Lichy $C$, Ringleb PA, Hacke W, et al. Point-of-care international normalized ratio testing accelerates thrombolysis in patients with acute ischemic stroke using oral anticoagulants. Stroke 2009;40:3547-3551.

21. Ebner $M$, Peter $A$, Spencer $C$, Härtig $F$, Birschmann I, Kuhn J, et al. Point-of-care testing of coagulation in patients treated with non-vitamin K antagonist oral anticoagulants. Stroke 2015;46:2741-2747.

22. van Ryn J, Baruch $L$, Clemens A. Interpretation of point-ofcare INR results in patients treated with dabigatran. Am J Med 2012;125:417-420.

23. Ebner M, Birschmann I, Peter $A$, Spencer $C$, Härtig $F$, Kuhn J, et al. Point-of-care testing for emergency assessment of coagulation in patients treated with direct oral anticoagulants. Crit Care 2017;21:32.

24. Mani $H$, Herth $N$, Kasper $A$, Wendt $T$, Schuettfort $G$, Weil $Y$, et al. Point-of-care coagulation testing for assessment of the pharmacodynamic anticoagulant effect of direct oral anticoagulant. Ther Drug Monit 2014;36:624-631.

25. Eikelboom J, Merli G. Bleeding with direct oral anticoagulants vs warfarin: clinical experience. Am J Med 2016;129 (11S):S33-S40.

26. Katsanos AH, Schellinger PD, Köhrmann M, Filippatou A, Gurol ME, Caso V, et al. Fatal oral anticoagulant-related intracranial hemorrhage: a systematic review and meta-analysis. Eur J Neurol 2018;25:1299-1302.

27. Steiner T, Al-Shahi Salman R, Beer R, Christensen H, Cordonnier C, Csiba L, et al. European Stroke Organisation (ESO) guidelines for the management of spontaneous intracerebral hemorrhage. Int J Stroke 2014;9:840-855.

28. Qureshi Al, Palesch YY, Barsan WG, Hanley DF, Hsu CY, Martin $\mathrm{RL}$, et al. Intensive blood-pressure lowering in patients with acute cerebral hemorrhage. N Engl J Med 2016; 375:1033-1043.

29. Mendelow AD, Gregson BA, Rowan EN, Murray GD, Gholkar $A$, Mitchell $P M$, et al. Early surgery versus initial conservative treatment in patients with spontaneous supratentorial lobar intracerebral haematomas (STICH II): a randomised trial. Lancet 2013;382:397-408.

30. Mendelow AD, Gregson BA, Fernandes HM, Murray GD, Teasdale GM, Hope DT, et al. Early surgery versus initial conservative treatment in patients with spontaneous supratentorial intracerebral haematomas in the International Surgical Trial in Intracerebral Haemorrhage (STICH): a randomised trial. Lancet 2005;365:387-397.

31. Boulouis G, Morotti A, Goldstein JN, Charidimou A. Intensive blood pressure lowering in patients with acute intracerebral haemorrhage: clinical outcomes and haemorrhage expansion. Systematic review and meta-analysis of randomised trials. J Neurol Neurosurg Psychiatry 2017;88:339-345.

32. Kuramatsu JB, Gerner ST, Schellinger PD, Glahn J, Endres M, Sobesky J, et al. Anticoagulant reversal, blood pressure levels, and anticoagulant resumption in patients with anticoagulation-related intracerebral hemorrhage. JAMA 2015;313:824836.

33. January CT, Wann LS, Alpert JS, Calkins $H_{1}$ Cigarroa JE, Cleveland JC Jr, et al. 2014 AHA/ACC/HRS guideline for the management of patients with atrial fibrillation: a report of the American College of Cardiology/American Heart Association task force on practice guidelines and the Heart Rhythm Society. J Am Coll Cardiol 2014;64:e1-e76.

34. Schulman $S$, Angerås U, Bergqvist D, Eriksson B, Lassen MR, Fisher $W_{1}$ et al. Definition of major bleeding in clinical investigations of antihemostatic medicinal products in surgical patients. J Thromb Haemost 2010;8:202-204.

35. Flibotte JJ, Hagan N, O'Donnell J, Greenberg SM, Rosand J. Warfarin, hematoma expansion, and outcome of intracerebral hemorrhage. Neurology 2004;63:1059-1064.

36. Hart RG, Boop BS, Anderson DC. Oral anticoagulants and intracranial hemorrhage. Facts and hypotheses. Stroke 1995; 26:1471-1477.

37. Rosand J, Hylek EM, O'Donnell HC, Greenberg SM. Warfarinassociated hemorrhage and cerebral amyloid angiopathy: a genetic and pathologic study. Neurology 2000;55:947-951.

38. Purrucker JC, Haas K, Rizos T, Khan S, Wolf M, Hennerici MG, et al. Early clinical and radiological course, management, and outcome of intracerebral hemorrhage related to new oral 
anticoagulants. JAMA Neurol 2016;73:169-177.

39. Tsivgoulis G, Lioutas VA, Varelas $P$, Katsanos AH, Goyal N, Mikulik $\mathrm{R}$, et al. Direct oral anticoagulant- vs vitamin $\mathrm{K}$ antagonist-related nontraumatic intracerebral hemorrhage. Neurology 2017;89:1142-1151.

40. Inohara T, Xian Y, Liang L, Matsouaka RA, Saver JL, Smith EE, et al. Association of intracerebral hemorrhage among patients taking non-vitamin $\mathrm{K}$ antagonist vs vitamin $\mathrm{K}$ antagonist oral anticoagulants with in-hospital mortality. JAMA 2018;319:463-473.

41. Pollack CV Jr, Reilly PA, Eikelboom J, Glund S, Verhamme P, Bernstein RA, et al. Idarucizumab for Dabigatran Reversal. $N$ Engl J Med 2015;373:511-520.

42. Pollack CV Jr, Reilly PA, van Ryn J, Eikelboom JW, Glund S, Bernstein RA, et al. Idarucizumab for dabigatran reversal: full cohort analysis. N Engl J Med 2017;377:431-441.

43. Kermer P, Eschenfelder CC, Diener HC, Grond M, Abdalla Y, Althaus $K$, et al. Antagonizing dabigatran by idarucizumab in cases of ischemic stroke or intracranial hemorrhage in Germany: a national case collection. Int J Stroke 2017;12:383-391.

44. Marlu R, Hodaj E, Paris A, Albaladejo P, Cracowski JL, Pernod G. Effect of non-specific reversal agents on anticoagulant activity of dabigatran and rivaroxaban: a andomized crossover ex vivo study in healthy volunteers. Thromb Haemost 2012;108:217-224.

45. Zhou W, Schwarting S, Illanes S, Liesz A, Middelhoff M, Zorn $M$, et al. Hemostatic therapy in experimental intracerebral hemorrhage associated with the direct thrombin inhibitor dabigatran. Stroke 2011;42:3594-3599.

46. Frontera JA, Lewin JJ 3rd, Rabinstein AA, Aisiku IP, Alexandrov AW, Cook AM, et al. Guideline for reversal of antithrombotics in intracranial hemorrhage: a statement for healthcare professionals from the Neurocritical Care Society and Society of Critical Care Medicine. Neurocrit Care 2016;24:6-46.

47. Siegal DM, Curnutte JT, Connolly SJ, Lu G, Conley PB, Wiens $\mathrm{BL}$, et al. Andexanet alfa for the reversal of factor Xa inhibitor activity. N Engl J Med 2015;373:2413-2424.

48. U.S. Food and Drug Administration (FDA). Accelerated approval of Andexxa. FDA. https://www.fda.gov/downloads/BiologicsBloodVaccines/CellularGeneTherapyProducts/ApprovedProducts/UCM606693.pdf. May 3, 2018. Accessed September 13, 2018.

49. Lu G, DeGuzman FR, Hollenbach SJ, Karbarz MJ, Abe K, Lee $\mathrm{G}$, et al. A specific antidote for reversal of anticoagulation by direct and indirect inhibitors of coagulation factor $\mathrm{Xa}$. Nat Med 2013;19:446-451.

50. Connolly SJ, Milling TJ Jr, Eikelboom JW, Gibson CM, Curnutte JT, Gold A, et al. Andexanet alfa for acute major bleeding asso- ciated with factor Xa inhibitors. N Engl J Med 2016;375:11311141.

51. Levi M, Moore KT, Castillejos CF, Kubitza D, Berkowitz SD, Goldhaber SZ, et al. Comparison of three-factor and fourfactor prothrombin complex concentrates regarding reversal of the anticoagulant effects of rivaroxaban in healthy volunteers. J Thromb Haemost 2014;12:1428-1436.

52. Gerner ST, Kuramatsu JB, Sembill JA, Sprügel MI, Endres M, Haeusler KG, et al. Association of prothrombin complex concentrate administration and hematoma enlargement in nonvitamin $\mathrm{K}$ antagonist oral anticoagulant-related intracerebral hemorrhage. Ann Neurol 2018;83:186-196.

53. Barco S, Whitney Cheung Y, Coppens M, Hutten BA, Meijers $J C$, Middeldorp S. In vivo reversal of the anticoagulant effect of rivaroxaban with four-factor prothrombin complex concentrate. Br J Haematol 2016;172:255-261.

54. Cheung YW, Barco S, Hutten BA, Meijers JC, Middeldorp S, Coppens $M$. In vivo increase in thrombin generation by fourfactor prothrombin complex concentrate in apixaban-treated healthy volunteers. J Thromb Haemost 2015;13:1799-1805.

55. Zahir H, Brown KS, Vandell AG, Desai M, Maa JF, Dishy V, et al. Edoxaban effects on bleeding following punch biopsy and reversal by a 4-factor prothrombin complex concentrate. Circulation 2015;131:82-90.

56. Heidbuchel $H$, Verhamme $P$, Alings $M$, Antz $M$, Diener $H C$, Hacke W, et al. Updated European Heart Rhythm Association practical guide on the use of non-vitamin-K antagonist anticoagulants in patients with non-valvular atrial fibrillation: executive summary. Eur Heart $J$ 2017;38:2137-2149.

57. Dibu JR, Weimer JM, Ahrens C, Manno E, Frontera JA. The role of FEIBA in reversing novel oral anticoagulants in intracerebral hemorrhage. Neurocrit Care 2016;24:413-419.

58. Leissinger CA, Blatt PM, Hoots WK, Ewenstein B. Role of prothrombin complex concentrates in reversing warfarin anticoagulation: a review of the literature. Am J Hematol 2008;83: 137-143.

59. Enriquez A, Lip GY, Baranchuk A. Anticoagulation reversal in the era of the non-vitamin K oral anticoagulants. Europace 2016;18:955-964.

60. Ansell JE, Bakhru SH, Laulicht BE, Steiner SS, Grosso M, Brown K, et al. Use of PER977 to reverse the anticoagulant effect of edoxaban. N Engl J Med 2014;371:2141-2142.

61. Ansell JE, Bakhru SH, Laulicht BE, Steiner SS, Grosso MA,

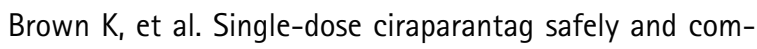
pletely reverses anticoagulant effects of edoxaban. Thromb Haemost 2017;117:238-245.

62. Sheffield WP, Lambourne MD, Eltringham-Smith $\sqcup$, Bhakta V, Arnold DM, Crowther MA. YT-S195A thrombin reduces the 
anticoagulant effects of dabigatran in vitro and in vivo. $J$ Thromb Haemost 2014;12:1110-1115.

63. Eckman MH, Rosand J, Knudsen KA, Singer DE, Greenberg SM. Can patients be anticoagulated after intracerebral hemorrhage? A decision analysis. Stroke 2003;34:1710-1716.

64. Morgenstern LB, Hemphill JC 3rd, Anderson C, Becker K, Broderick JP, Connolly ES Jr, et al. Guidelines for the management of spontaneous intracerebral hemorrhage: a guideline for healthcare professionals from the American Heart Association/American Stroke Association. Stroke 2010;41: 2108-2129.

65. Steiner T. Resumption of oral anticoagulation after warfarinassociated intracerebral hemorrhage: yes. Stroke 2011;42: 3661-3662.

66. Hernandez I, Zhang Y, Brooks MM, Chin PK, Saba S. Anticoagulation use and clinical outcomes after major bleeding on dabigatran or warfarin in atrial fibrillation. Stroke 2017;48: 159-166.

67. Molina $\mathrm{CA}$, Selim MH. The dilemma of resuming anticoagulation after intracranial hemorrhage: little evidence facing big fears. Stroke 2011;42:3665-3666.

68. Paciaroni M, Agnelli G. Should oral anticoagulants be restarted after warfarin-associated cerebral haemorrhage in patients with atrial fibrillation? Thromb Haemost 2014;111:14-18.

69. Biffi A, Kuramatsu JB, Leasure A, Kamel H, Kourkoulis $C$, Schwab $K$, et al. Oral anticoagulation and functional outcome after intracerebral hemorrhage. Ann Neurol 2017;82: 755-765.

70. Nielsen PB, Larsen TB, Skjøth F, Gorst-Rasmussen A, Rasmussen LH, Lip GY. Restarting anticoagulant treatment after intracranial hemorrhage in patients with atrial fibrillation and the impact on recurrent stroke, mortality, and bleeding: a nationwide cohort study. Circulation 2015;132:517-525.

71. Purrucker JC, Steiner T. Management of acute stroke in patients on oral anticoagulants. Curr Opin Neurol 2017;30:1-7.

72. Horstmann S, Zugck C, Krumsdorf U, Rizos T, Rauch G, Geis $\mathrm{N}$, et al. Left atrial appendage occlusion in atrial fibrillation after intracranial hemorrhage. Neurology 2014;82:135-138.

73. Sahay S, Nombela-Franco L, Rodes-Cabau J, Jimenez-Quevedo P, Salinas P, Biagioni C, et al. Efficacy and safety of left atrial appendage closure versus medical treatment in atrial fibrillation: a network meta-analysis from randomised trials. Heart 2017;103:139-147.

74. Reddy VY, Doshi SK, Kar S, Gibson DN, Price MJ, Huber K, et al. 5-Year outcomes after left atrial appendage closure: from the PREVAIL and PROTECT AF trials. J Am Coll Cardiol 2017; 70:2964-2975.

75. Hemphill JC 3rd, Greenberg SM, Anderson CS, Becker K, Bendok BR, Cushman $M$, et al. Guidelines for the management of spontaneous intracerebral hemorrhage: a guideline for healthcare professionals from the American Heart Association/American Stroke Association. Stroke 2015;46:20322060. 